\title{
A novel dominant glossy mutation causes suppression of wax biosynthesis pathway and deficiency of cuticular wax in Brassica napus
}

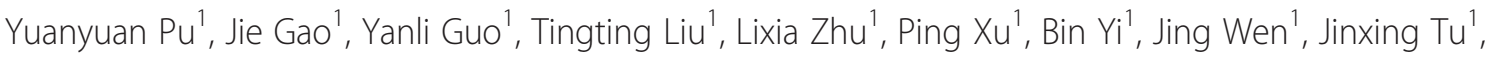 \\ Chaozhi Ma', Tingdong Fu', Jitao Zou' ${ }^{2}$ and Jinxiong Shen ${ }^{1 *}$
}

\begin{abstract}
Background: The aerial parts of land plants are covered with cuticular waxes that limit non-stomatal water loss and gaseous exchange, and protect plants from ultraviolet radiation and pathogen attack. This is the first report on the characterization and genetic mapping of a novel dominant glossy mutant (BnaA.GL) in Brassica napus.

Results: Transmission electron microscopy revealed that the cuticle ultrastructure of GL mutant leaf and stem were altered dramatically compared with that of wide type (WT). Scanning electron microscopy corroborated the reduction of wax on the leaf and stem surface. A cuticular wax analysis of the GL mutant leaves further confirmed the drastic decrease in the total wax content, and a wax compositional analysis revealed an increase in aldehydes but a severe decrease in alkanes, ketones and secondary alcohols. These results suggested a likely blockage of the decarbonylation step in the wax biosynthesis pathway. Genetic mapping narrowed the location of the BnaA.GL gene to the end of A9 chromosome. A single-nucleotide polymorphism (SNP) chip assay in combination with bulk segregant analysis (BSA) also located SNPs in the same region. Two SNPs, two single sequence repeat (SSR) markers and one IP marker were located on the flanking region of the BnaA.GL gene at a distance of $0.6 \mathrm{cM}$. A gene homologous to ECERIFERUM1 (CER1) was located in the mapped region. A cDNA microarray chip assay revealed coordinated down regulation of genes encoding enzymes of the cuticular wax biosynthetic pathway in the glossy mutant, with BnCER1 being one of the most severely suppressed genes.
\end{abstract}

Conclusions: Our results indicated that surface wax biosynthesis is broadly affected in the glossy mutant due to the suppression of the BnCER1 and other wax-related genes. These findings offer novel clues for elucidating the molecular basis of the glossy phenotype.

Keywords: Brassica napus, Glossy mutant, Genetic mapping, Wax biosynthesis, Microarray assays, Candidate genes

\section{Background}

The plant cuticle acts as a hydrophobic layer to protect land plants against biotic and abiotic stresses. The cuticle layer is primarily composed of polymeric cutin and lipidic cuticular wax [1,2]; the cutin polymer is the framework, and waxes are interspersed within the cutin. Cuticular wax provides a protective barrier to biotic and abiotic stresses, including drought, pests, pathogens and UV radiation $[3,4]$, and defects result in perturbed cuticle

\footnotetext{
* Correspondence: jxshen@mail.hzau.edu.cn

${ }^{1}$ National Key Laboratory of Crop Genetic Improvement, Huazhong

Agricultural University, Wuhan 430070, China

Full list of author information is available at the end of the article
}

permeability. Cuticular wax biosynthesis is regulated in response to drought, reducing water loss rates in some plants [5-7]. Arabidopsis [8-10], rice [11,12] and tomato $[13,14]$ mutants with wax alterations display sparse crystals on the surface of aerial organs and enhanced sensitivity to drought. Deficiency in cuticular wax has also been correlated with organ fusions and reduced fertility $[8,15,16]$.

The aliphatic constituents of waxes are derived from saturated very long chain fatty acid. Fatty acids with chain length of up to $\mathrm{C} 16$ and $\mathrm{C} 18$ are synthesized in the plastids and subsequently exported to the cytoplasm where they are further elongated to very long-chain fatty

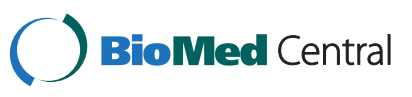

(c) 2013 Pu et al.; licensee BioMed Central Ltd. This is an open access article distributed under the terms of the Creative Commons Attribution License (http://creativecommons.org/licenses/by/2.0), which permits unrestricted use, distribution, and reproduction in any medium, provided the original work is properly cited. 
acids (VLCFAs; C20 to C34) through the sequential addition of two-carbon units in a reaction catalyzed by fatty acid elongase complexes in the endoplasmic reticulum [1,2]. Cuticular waxes contain species-specific compound classes and carbon chain length patterns $[1,2]$. In Arabidopsis, the cuticular wax of stems consists of VLCFA alkanes, aldehydes, fatty acids, primary alcohols, wax esters, secondary alcohols and ketones, with 80-90\% alkanes, secondary alcohols and ketones $[17,18]$. The biosynthesis of these compounds involves two pathways: the acyl-reduction pathway in which primary alcohols and wax esters are synthesized and the decarbonylation pathway through which aldehydes, alkanes, ketones and secondary alcohols are synthesized [18].

In Arabidopsis, the cer1-1 mutant is characterized by a drastic decrease in the products of the alkane-forming pathway (alkanes, secondary alcohols and ketones) and a corresponding increase in aldehydes [19-21]. The product of the ECERIFERUM (CER1) functions as a putative aldehyde decarbonylase $[19,20]$, and it was recently shown that CER1 interacts with the wax-associated gene CER3 and cytochrome b5 isoforms (CYTB5s) [22]. CER1 homologs are present in both dicot and monocot species and are structurally conserved. Additionally, all CER1 proteins contain iron-binding (histidine-rich) motifs, suggesting that CER1 homologous proteins have a similar function among organisms [19].

Normally, the waxless character is controlled by recessive genes. To our knowledge, there have been few reports of dominant mutations. In wheat, the inheritance of glaucousness is mainly governed by two sets of dominant genes, $W 1$ and $W 2$, which promote a glaucous phenotype, and $I w 1$ and $I w 2$, which inhibit it. $W 1$ and $I w 1$ are located on the short arm of chromosome $2 \mathrm{~B}$ (2BS) and $W 2$ and Iw2 on 2DS [23]. Recently, a genetic approach with the detailed biochemical characterization of wax compounds was used to characterize the Iw1 locus, which inhibits the formation of $\beta$ - and hydroxy- $\beta$-diketones in the peduncle and flag leaf blade cuticles. This inhibitory effect was found to be independent of the genetic background or tissue and was accompanied by minor but consistent increases in n-alkanes and C24 primary alcohols [24]. In banana, the ratio of waxy versus nonwaxy pseudostem in the cross SH-3362 $\times$ Long Tavoy was $1: 1\left(x^{2}=0.22\right)$, indicating that the genotypes of SH-3362 and Long Tavoy should be $w x w x$ and $W x w x$, respectively. The $\mathrm{F}_{1} \mathrm{ob}-$ tained by crossing FR (slight pseudostem waxiness) $\times \mathrm{C} 4$ (nonwaxy pseudostem) were glossy, and the $\mathrm{F}_{2}$ segregated for this trait (glossy: $\operatorname{wax}=3: 1, \mathrm{x}^{2}=1.15$ ) indicating that the nonwaxy pseudostem may be a single dominant in this population, and that the genotype of C4 should be $W x W x$. But in other segregating populations the situation was more complex, suggesting that genetic modifiers can overcome the action of the $W x$ allele [25].
Although wax-deficient mutants have been isolated in a number of plant species [26,27], there are few reports focused on the study of cuticular wax in Brassica species $[28,29]$. Since 1990 , breeders have focused on the genetic analysis of the wax-less phenotype and have suggested that this feature can be used as a morphological marker in hybrid breeding. Recently, in Brassica rapa, the BrWax1 (Brassica Wax) gene was located to a $86.4 \mathrm{~kb}$ genomic DNA fragment on linkage group A1. Bra013809, the homologous gene of CER2 was speculated to be the candidate gene [30].

To our knowledge, this is the first report on the characterization and genetic mapping of a dominant glossy mutant (BnaA.GL) in B. napus. The GL mutant exhibited a drastic decrease in wax and enhanced cuticle permeability. Linkage of SNP markers to the BnaA.GL gene were achieved using an SNP chip assay combined with BSA, and the BnaA.GL gene was localized to the end of the B. napus A9 chromosome. The B. napus GL mutant was found to share biochemical characteristics of the cer1-1 mutant in Arabidopsis thaliana. Additionally, a gene homologous to CER1 was found to be located in the candidate region. A cDNA microarray assay showed that the expression of a group of genes encoding cuticular wax biosynthetic enzymes and fatty acid synthesis were downregulated in the leaf tissues of the glossy mutant. We found that the BnCER1 gene was dramatically suppressed in the $G L$ mutant but no mutation affecting the function of the BnCER1 gene was obvious. We conclude that the BnaA.GL mutation caused down-regulation of cuticular wax biosynthetic genes, particularly the CER1 gene. Since the BnaA.GL allele behaves in a dominant fashion in regulating wax biosynthesis, this glossy mutant is unique from other cer mutants reported to date and may prove useful for future study on the regulation of wax biosynthesis pathways in plants.

\section{Result}

\section{Identification of the $G L$ mutant}

The GL mutant (6-1025) was initially discovered from a large breeding population. In this project line 6-3476 was used as the wide type to cross with GL mutant 6-1025 to generate $F_{1}$ seeds. One $F_{1}$ plant derived from this cross was then used to develop a double haploid $(\mathrm{DH})$ population through microspore culture as described in a previous report [31]. In these $\mathrm{DH}$ lines there was clear segregation in terms of the glossy phenotype. We selected line-7 (DH line-7) and line-69 (DH line-69) which both exhibited a distinctive glossy phenotype, and line-2 (DH line-2), and line-3 (DH line-3) that appeared normal for further study.

The $\mathrm{F}_{1}$ (or $\mathrm{RF}_{1}$ ) plants of reciprocal crosses between WT and the GL mutant were all glossy, indicating that the glossy trait was dominant. The $\mathrm{BC}_{1}$ progeny developed from the crosses between the $\mathrm{F}_{1}$ plant and WT displayed a 
1:1 ratio of glossy to normal plants. Moreover, the glossy to normal phenotype ratio in the $F_{2}$ population was approximately 3:1 (Table 1), indicating that this was a case in which one Mendelian locus controlled the glossy trait. The glossy gene was tentatively designated as the BnaA.GL gene.

\section{Abnormal epidermis formed and water permeability increased in the GL mutant}

The glossy phenotype of the GL mutant's leaf and stem surface is shown in Figure 1B, D. Scanning electron microscopy (SEM) was also used to assess the density of wax crystals on leaf and stem tissue. This revealed a clear reduction of wax crystals in some regions of leaf surface (Figure 2A-D). Leaf and stem cross sections were further examined using transmission electron microscopy (TEM), which indicated that that the cuticle ultrastructure of $G L$ mutant leaf (Figure 2F) and stem (Figure 2H) were altered dramatically compared with that of WT leaf (Figure 2E) and stem (Figure 2G). The cuticle membrane (cuticle proper plus cuticular layer) of GL leaf and stem were less osmiophilic, as indicated by the reduced electron density, but more thick compared with those of wild type, especially the stem.

A distorted cuticular layer often results in an increased permeability of leaves [32-34]. To test this, we incubated 4 weeks old leaves with Toluidine Blue (TB) solution $(0.05 \% \mathrm{w} / \mathrm{v})$ for $2 \mathrm{~min}$, and assessed the staining intensities. As show in (Figure 3C, D left), WT leaves were barely stained whereas many parts of the mutant leaves were heavily stained (Figure 3C, D right). Furthermore, the GL mutant rapidly lost chlorophyll content and showed a significantly higher water loss rate when compared with WT (Additional file 1). These results were consistent with the observation that the cuticular layer of the leaf was abnormal, thus suggesting that the mutants were compromised in the strength of water permeability barrier.

\section{Decrease in total cuticular waxes and alteration of wax composition in the GL mutant}

To dissect the changes in chemical components that were responsible for the glossy phenotype, we used thin-layer chromatography (TLC) for quantitative and compositional analyses of leaf wax extracts. TLC analysis revealed a distinctively different pattern of wax composition in the mutants (Figure 4). The GL mutant and DH line-7 had total wax coverage of $3.2 \mu \mathrm{g} / \mathrm{cm}^{2}$ and $6.4 \mu \mathrm{g} / \mathrm{cm}^{2}$, which

Table 1 Segregation of glossy trait in the BC1 and F2 progenies of two crosses

\begin{tabular}{cccccc}
\hline Combination & Population & $\begin{array}{c}\text { No. of } \\
\text { glossy }\end{array}$ & $\begin{array}{c}\text { No. of } \\
\text { wax }\end{array}$ & $\begin{array}{c}\text { Expected } \\
\text { ratio }\end{array}$ & $\mathbf{P}$ \\
\hline WT $\times$ mutant & BC1 & 128 & 117 & $1: 1$ & 0.48 \\
& $F 2$ & 278 & 113 & $3: 1$ & 0.08 \\
\hline
\end{tabular}

represented a reduction of $89 \%$ and $77 \%$, respectively, when compared with the wild type and $\mathrm{DH}$ line-2 (Table 2).

Looking into different cuticular wax compound classes, alkanes, secondary alcohols ( $2^{\circ}$ alcohols) and ketones were not detectable (or below detection limits) in the mutants (Figure 4; Table 2). We also detected reductions in both primary alcohols and wax esters. There was also a several fold reduction in wax esters, which were found at $0.1 \mu \mathrm{g}$ / $\mathrm{cm}^{2}$ and $0.3 \mu \mathrm{g} / \mathrm{cm}^{2}$ in the GL mutant and $\mathrm{DH}$ line-7, respectively, while the WT and the DH line-2 had wax esters at $0.6 \mu \mathrm{g} / \mathrm{cm}^{2}$ and $0.7 \mu \mathrm{g} / \mathrm{cm}^{2}$. Primary alcohols were found at $0.3 \mu \mathrm{g} / \mathrm{cm}^{2}$ and $0.5 \mu \mathrm{g} / \mathrm{cm}^{2}$ in the GL mutant and $\mathrm{DH}$ line-7, respectively, while the WT and the $\mathrm{DH}$ line-2 had levels of at $0.7 \mu \mathrm{g} / \mathrm{cm}^{2}$ and $0.8 \mu \mathrm{g} / \mathrm{cm}^{2}$, respectively (Table 2). Against the backdrop of reduction in all these compound classes, our analysis revealed clear increases in the content of the aldehydes, which in both the GL mutant and DH line- 2 were at approximately 3 fold of that of the WT (Table 2).

Previous studies have shown that mutations in CER1 block the conversion of stem wax C30 aldehydes (triacontanal) to C29 alkanes (nonacosane), and the secondary alcohols and ketones were also reduced in the mutants $[19,20]$. Because alkanes, secondary alcohols and ketones are major components of total wax, the lack of these three components would be expected to negatively impact the overall wax coverage $[17,18]$. Furthermore, the accumulation of aldehydes was also consistent with the deficiency of the CER1 step that converts aldehyde to alkandes in the GL mutant (Figure 4; Table 1; Figure 5).

\section{Fine mapping of the BnaA.GL gene}

Our initial mapping using the glossy leaf phenotype as a morphological marker (named Y) mapped the genetic lesion to linkage group A9 from an $F_{2}$ population derived from a cross between WT and the glossy mutant. SSR and AFLP markers were assembled into a genetic linkage map with JOINMAP 3.0 (Figure 6A). We then developed seven amplified fragment-length polymorphism (AFLP) markers linked to the BnaA.GL gene using an AFLP assay in combination with BSA [35]. Only two of the markers were converted into useful sequence-characterized amplified region (SCAR) markers, and the SCAR marker 1616-1 was detected in the flanking region of the BnaA.GL gene (Figure 6B). Additional SSR markers were pursued based on a bacterial artificial chromosome (BAC) sequence close to the end of the $B$. rapa $\mathrm{R} 9$ chromosome (Figure 6D), resulting in two more SSR markers mapped to the flanking region of the BnaA.GL gene (Figure 6B) $[36,37]$. Since the BAC "KBrB043F18" was located on the very end of A9 [38] (Figure 6C), we developed markers based on the BAC sequences, but no molecular markers with polymorphism were detected based on the sequence 

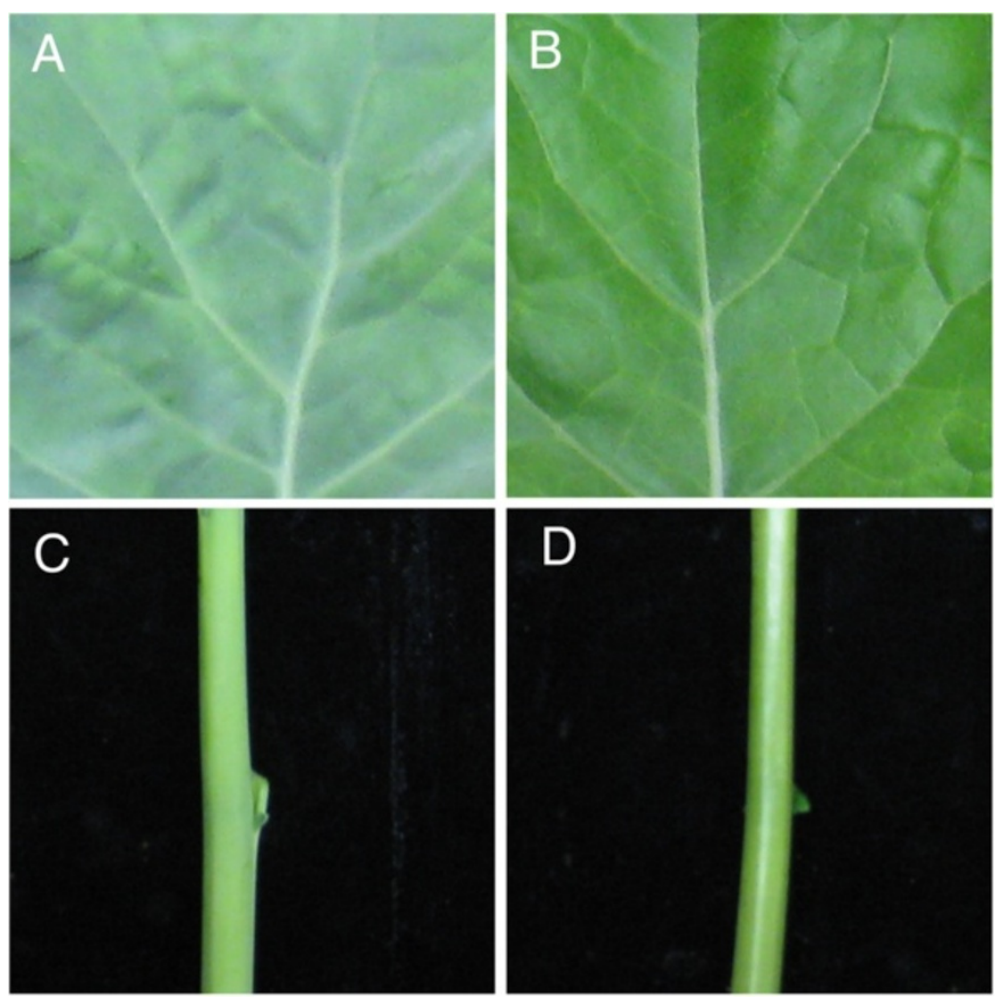

Figure 1 Morphological characters of WT and the GL mutant. The leaf (A) and stem (C) of WT appear glaucous, as compared to the glossy phenotype of the GL mutant leaf (B) and stem (D).

of BAC "KBrB043F18" (Figure 6B, C, D). IP markers were designed based on a previous report [39], and one IP marker CIP12 was detected in the flanking region of the BnaA.GL gene (Figure 6B). Based on 300 normal individuals from a $\mathrm{BC}_{3} \mathrm{~F}_{2}$ population (1200), all markers were used to survey the population. After genotype testing of all individuals in the mapping population, 4 individuals displaying recombination between BnaA.GL and IGF5706e were identified. The distance between IGF5706e and BnaA.GL was $1.33 \mathrm{cM}$. Among the 4 identified recombinants, 3 of the individuals displayed recombination between the BnaA.GL gene and 1616-1, and the distance between 1616-1 and BnaA.GL was 1 cM. In addition, 2 recombinants displayed recombination between BnaA.GL and the other SSR and IP markers, the distance between these markers and the BnaA.GL gene was 0.67 cM. All markers were on the same side of the BnaA.GL gene. These markers were mapped to a region of $0.67-1.33 \mathrm{cM}$ in the flanking region of the BnaA.GL gene. Unfortunately, we failed to find any markers on the other side of the BnaA.GL gene. Compared to $B$. rapa, there appears to be an inversion at the end of the B. napus chromosome [38] (Figure 6B, $\mathrm{C}, \mathrm{D})$. All markers linked to the gene were used to compare the micro-colinearity of the regions flanking the genes with B. rapa and Arabidopsis (Figure 7).
Transcriptome analysis uncovered different expression pattern in the mutants

In search of clues underlying the molecular basis of the glossy phenotype, we then conducted a microarray analysis using RNA from leaf tissue of similar developmental stages and performed a comparison of the global transcript level between WT vs. the GL mutant and double haploid normal line bulk (DHNB) segregates vs. $\mathrm{DH}$ glossy line bulk (DHGB) segregates. In the wild type vs. GL mutant analysis, 619 genes were detected as DEGs (differentially expressed genes): 232 DEGs showed a higher expression level in wild type, whereas 387 DEGs showed a higher expression level in the $G L$ mutant (Figure 5A; Additional file 2). A total of 184 genes were determined to be DEGs in the analysis between the bulked glossy DH lines and the bulked normal DH lines (DHNB vs. DHGB), with 55 showing a higher expression level in DHNB and 129 showing a higher level in DHGB (Figure 5A; Additional file 2). We could identify 55 shared genes showing differential expression profiles through both sets of microarray experiments, among which 12 genes were more highly expressed in normal plants, and 23 genes were more highly expressed in glossy plants (Figure 5A; Additional file 2). Despite the fact that the phenotype was distinguished based on wax content, the Gene Ontology (GO) 

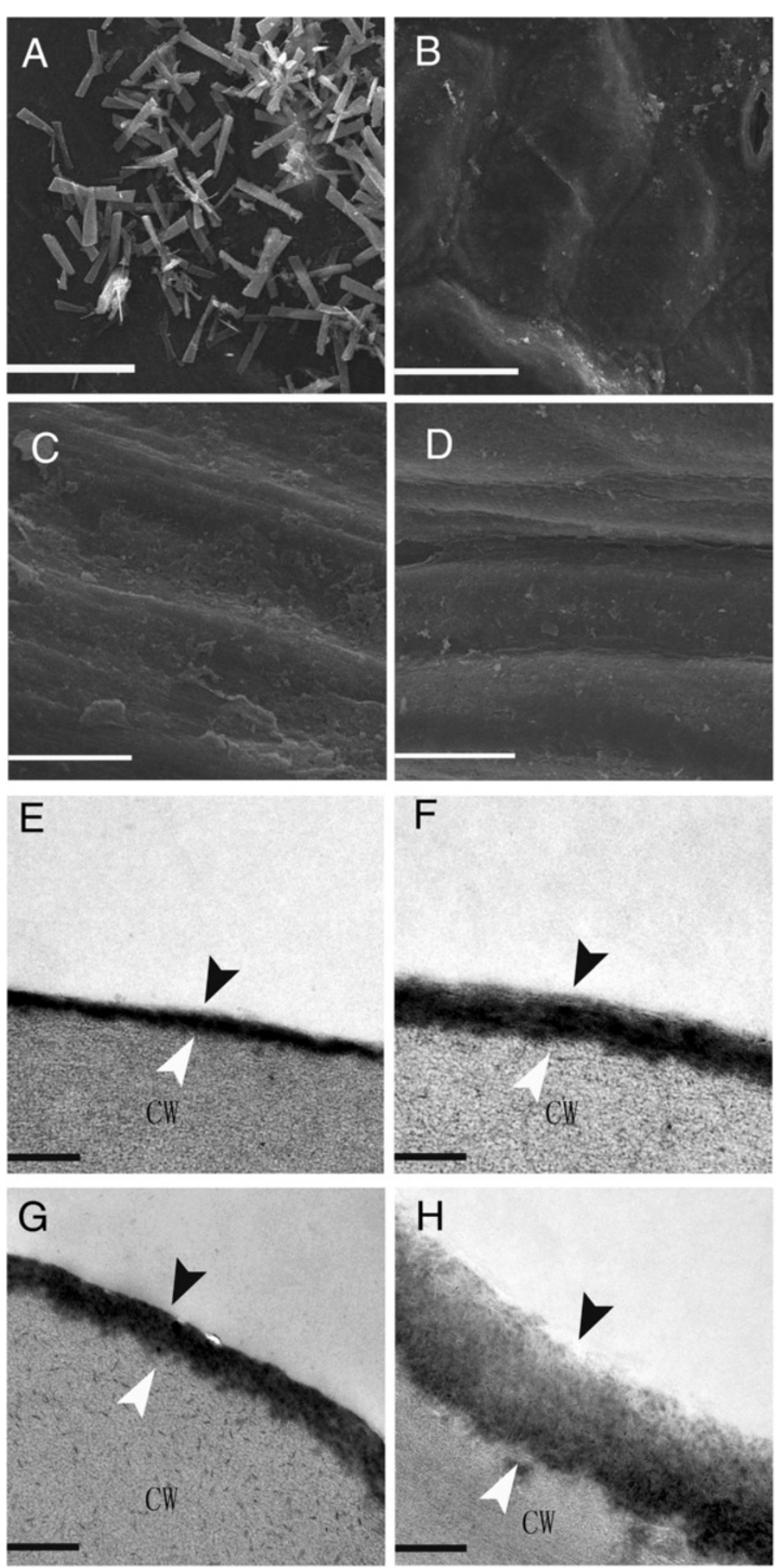

Figure 2 (See legend on next page.) 
(See figure on previous page.)

Figure 2 Epicuticular wax and cuticle layer of WT and the GL mutant. (A-D) Scanning electron microscopy. (A) Wax crystals on the WT leaf were dense, with high proportion of tubular-like wax crystals. (B) Wax crystals sparsely distributed on the leaf of the GL mutant. Bar =20 $\mu$ m. (C) Wax crystals on the WT stem with a high proportion of plate-like wax crystals. (B) Fewer wax crystals were present on the stem of the $G L$ mutant. Bar $=10 \mu \mathrm{m}$. (E-H) Transmission electron microscopy. The leaf and stem cuticle proper is indicated by black arrowheads and the cuticle layer is indicated by white arrowheads. The cuticle ultrastructure of GL mutant leaf $\mathbf{( F )}$ and stem $(\mathbf{H})$ were altered dramatically compared with that of WT leaf (E) and stem (G). The cuticle membrane (cuticle proper plus cuticular layer) of GL leaf and stems was thicker, and less osmiophilic. Bar =200 nm.

term categorization for both comparisons indicated that the majority of genes indentified are related to stress responses and to abiotic or biotic stimuli (Additional file 2; Additional file 3). For the genes related to lipid metabolism, only 29 genes were up-regulated and same number of genes were down-regulated in the wild type vs. GL mutant analysis; in DHNB vs. DHGB analysis, the number of up- and down-regulated genes were 11 and 5 (Additional file 3).

\section{Wax biosynthetic genes are down-regulated in the glossy mutant}

A major functional category of the down-regulated genes emerged from the DHNB vs. DHGB microarray analysis included those encoding a subset of genes related to the wax biosynthesis pathway (Figure 5). The aliphatic components of cuticular waxes are derived from saturated very-long-chain fatty acids [4]. The homolog of a gene encoding the biotin carboxyl carrier protein (BCCP), a component of the acetyl-CoA carboxylase that catalyzes the first committed step of fatty acid synthesis in the plastids, was down regulated in the GL mutant (Figure 5B, 5C). Similarly, the homolog of a gene encoding the 3-oxoacyl-

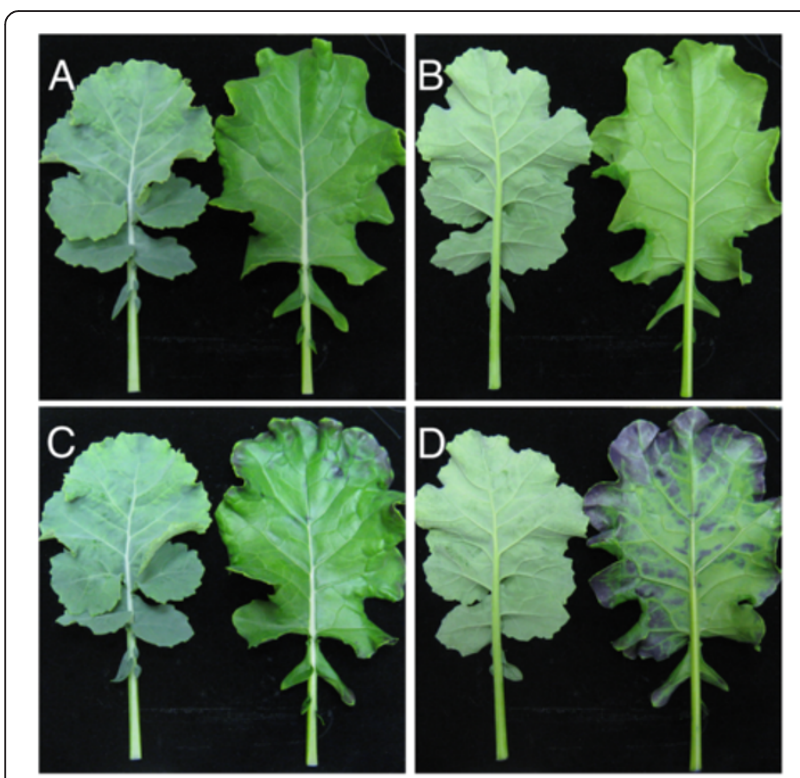

Figure 3 Defective cuticle in the $G L$ mutant. Toluidine blue staining pattern of $W T$ and the $G L$ mutant. WT (left), mutant (right). Before staining (A, B), after staining $(\mathbf{C}, \mathbf{D})$.
ACP reductase of the fatty acid synthase was also expressed at a lower level. The homolog of gene FATB, the acyl-acyl carrier protein thioesterase primarily responsible for hydrolyzing saturated acyl-ACPs to release saturated fatty acids into the cytosolic compartment, was reduced as well. Collectively, these results suggest that, at least at the transcript level, enzymes involved in the production of saturated fatty acids and precursors of the aliphatic components of waxes were negatively regulated in the leaf tissues of the GL mutant.

After the production of very long chain fatty acyl-CoAs, the biosynthesis of cuticular wax proceeds through two main pathways: an acyl reduction pathway, which produces primary alcohols and wax esters, and a decarbonylation pathway that generates aldehydes, alkanes, secondary alcohols and ketones. The putative aldehyde decarbonylase, CER1, and the midchain alkane hydroxylase, $M A H 1$, are involved in the decarbonylation branch of the wax biosynthesis [18-20, 40-42]. Homologs of both CER1 and MAH1 were found to be down regulated, suggesting that the decarbonylation pathway was suppressed. Reduction of transcript levels of the homo$\log$ of the bifunctional enzyme wax synthase (WSD1)

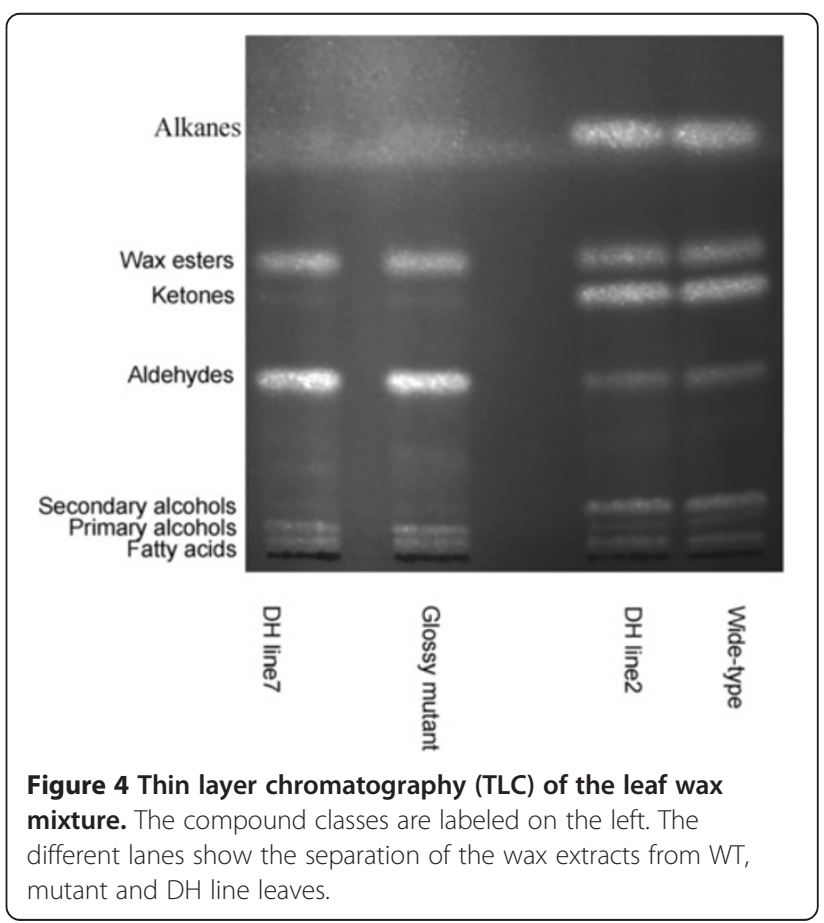


Table 2 Cuticular wax composition of wild-type, mutant and DH line

\begin{tabular}{ccccccccc}
\hline Line & Total & Alkanes & Wax esters & Ketones & Aldehydes & Secondary alcohols & Fatty acids & Primary alcohols \\
\hline Wide-type & $29.4 \pm 0.4$ & $16.2 \pm 0.5$ & $0.6 \pm 0.2$ & $7.8 \pm 0.2$ & $1.1 \pm 0.5$ & $2.8 \pm 0.5$ & $0.3 \pm 0.1$ & $0.7 \pm 0.2$ \\
Glossy mutant & $3.2 \pm 0.4$ & - & $0.1 \pm 0.0$ & - & $2.7 \pm 0.4$ & - & $0.2 \pm 0.0$ & $0.3 \pm 0.0$ \\
DH line-2 & $27.4 \pm 3.7$ & $13.9 \pm 0.4$ & $0.7 \pm 0.4$ & $5.9 \pm 2.3$ & $1.7 \pm 0.4$ & $4.1+1.1$ & $0.2 \pm 0.1$ & $0.8 \pm 0.4$ \\
DH line-7 & $6.4 \pm 2.0$ & - & $0.3 \pm 0.1$ & - & $4.9 \pm 1.3$ & - & $0.7 \pm 0.4$ & $0.5 \pm 0.4$ \\
\hline
\end{tabular}

Total wax content and coverage of individual compound classes $\left(\mu \mathrm{g} / \mathrm{cm}^{2}\right)$ were given as mean values $\pm S E(n=3)$. "-" and 0.0 denote values that were below $0.05 \mu \mathrm{g} / \mathrm{cm}^{2}$

gene [42] (Figure 5C) indicated that the acyl reduction pathway of wax biosynthesis was likely affected negatively as well in the GL mutant. The different expression patterns of these genes in the GL mutants were verifiable by quantitative real-time PCR (qRT-PCR) (Figure 5D).

Among the differentially expressed genes found in the GL mutants, BnCER1, the homolog of CER1 (At1g02205), was the most severely down-regulated. To investigate the expression patterns of $B n C E R 1$ in different tissues of $B$. napus plants, RT-PCR (semi quantitative RT-PCR) was performed using RNA prepared from 4-week-old stems, leaves and buds. BnCER1 was present at much higher levels in all the WT tissues examined (Figure 8), in accordance with a previously published report [20].

\section{BnCER1 gene sequence analysis}

Based on the available genome information $[37,43]$, there was approximately $250 \mathrm{~kb}$ between the closest marker SNP6 and Bra032670 at the end of chromosome R9 in

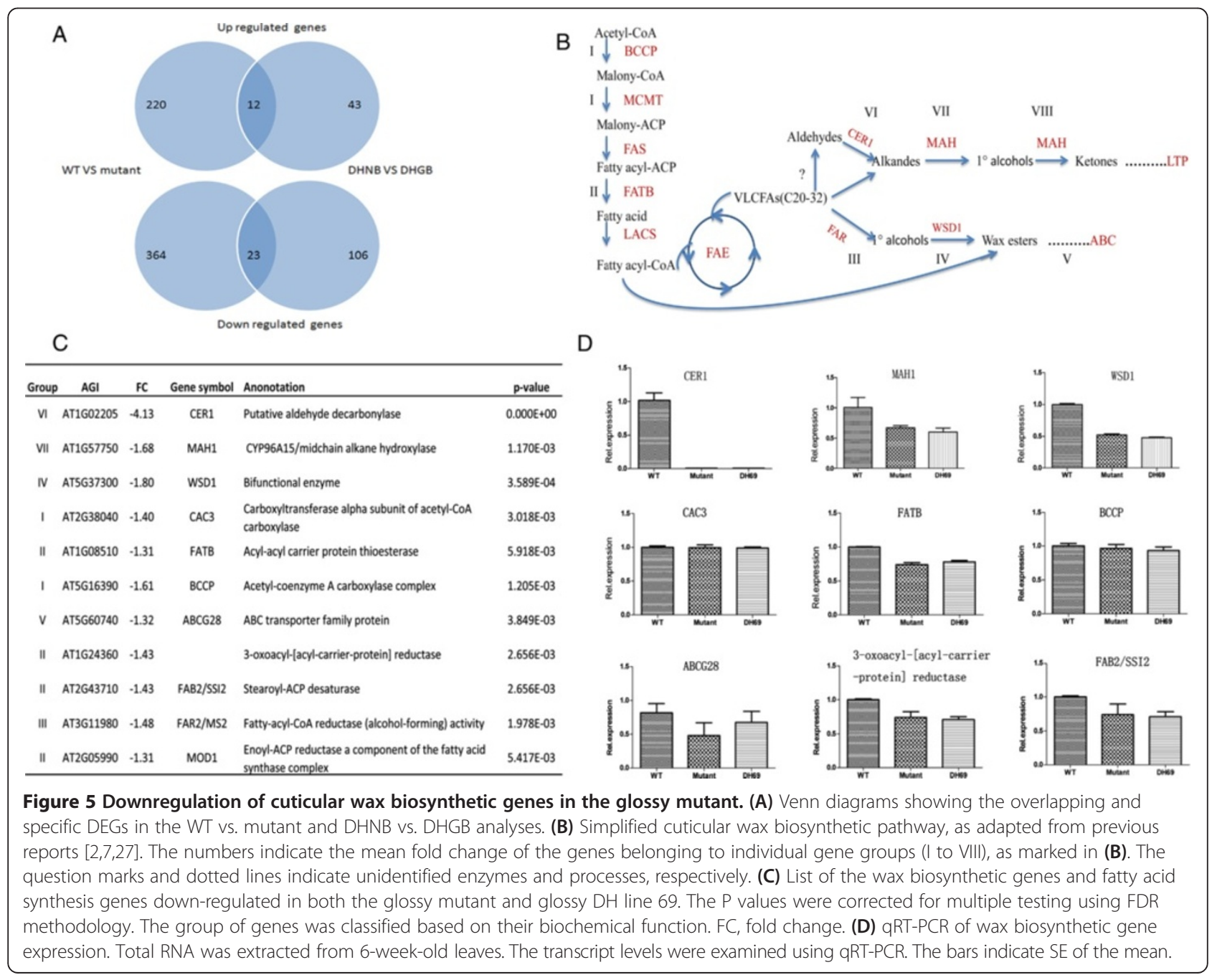




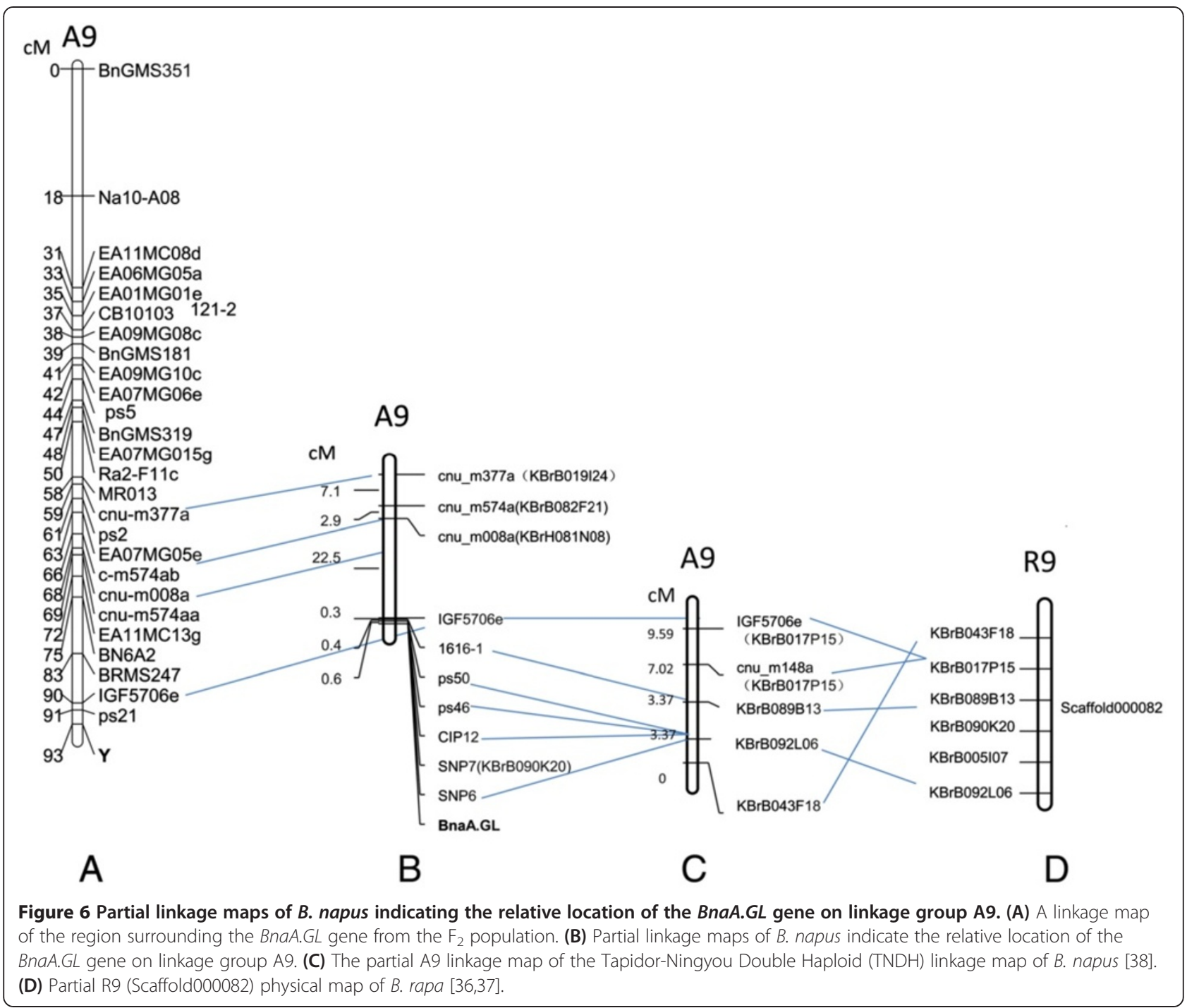

B. rapa. Although we failed to detect markers on the other side of the gene, the results suggested that this chromosome region could be a candidate for fine mapping and cloning of the gene. In light of the fact that Bra032670 at the end of the chromosome was homologous to CER1 (AT1G02205), the genetic lesion responsible for the glossy phenotype in Arabidopsis, we designed primers and amplified this gene sequence. It was found that the Bra032670 gene has a length of $4.41 \mathrm{~kb}$, with ten exons and nine introns. At least four copies of the CER1 otholog gene were identified from the allotetraploid oil crop species $B$. napus. However, there was no apparent sequence alteration between WT and the GL mutant except in the fifth intron where three SNPs were identified (Figure 9; Additional file 4). Our results thus suggested that the BnaA.GL mutation directly resulted in the down-regulation of cuticular wax biosynthetic genes, particularly the CER1 gene, leading to a deficiency of wax decarbonylation and, consequently, reduced wax deposition. Unlike previous reports in wax biosynthesis regulation, the BnaA.GL allele behaves in a dominant fashion.

\section{Discussion}

The decarbonylation pathway of wax biosynthesis was compromised in the GL mutant

The GL mutant features a glossy phenotype similar to the Arabidopsis cer1-1 mutant. CER1 was speculated to be an aldehyde decarbonylase, which catalyzes alkane biosynthesis through the decarboxylation pathway $[19,20]$. Data of wax composition analysis of the $G L$ mutant also revealed biochemical characteristics resembling that of the Arabidopsis cer1-1 [20]. Indeed, the wax compositional alterations were accentuated by decreases in the metabolites of the decarbonylation pathway, alkanes, secondary alcohols and ketones. There was also a conspicuous 


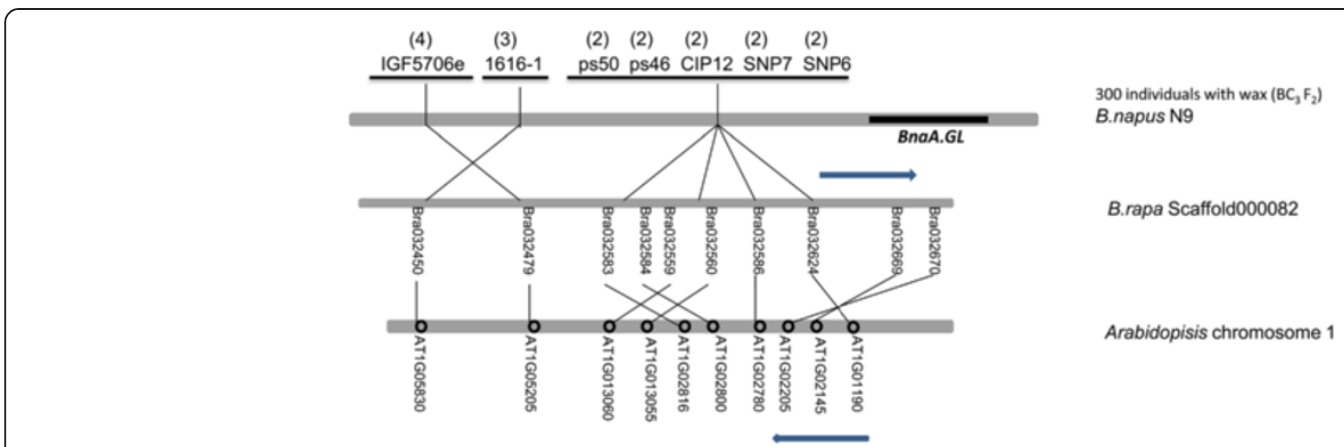

Figure 7 Comparative mapping of the BnaA.GL gene. Comparative analysis of the mapping region showing B. rapa genes and Arabidopsis genes [37,39].

increase in proportions of aldehydes, the precursors of the metabolic step mediated by CER1. In comparison to the Arabidopsis cer 1 mutant, the deficiency of alkanes, secondary alcohols and ketones in the GL mutant was more extreme, consequently resulting in a dramatic reduction of total wax $[17,18]$. Thus, results of our biochemical analysis as a whole clearly indicate that the decarbonylation pathway of wax biosynthesis was compromised in the GL mutant, evidenced by the fact that alkanes, and the primary candidate gene for alkane synthesis CER1, were affected most.

\section{Mapping in B. napus}

Our genetic analysis conclusively show that the glossy phenotype of the $G L$ mutant is determined by a single Mendelian locus, BnaA.GL. But unlike the cer1 mutant and all other wax biosynthesis mutants reported to date, the BnaA.GL locus acts in a dominant manner since reciprocal crosses between WT and the GL mutant were all glossy. We were able to map the genetic lesion to a linkage group close to the end of chromosome A9. Unfortunately, we failed to identify markers on the other side of the BnaA.GL gene, possibly due to the high level of relatedness of the parents. We are attempting to construct a larger population using a different line as the WT parent. This may allow us to reduce the interval covering the $B n a A . G L$ gene, enabling us to predict the candidate genes within the region.

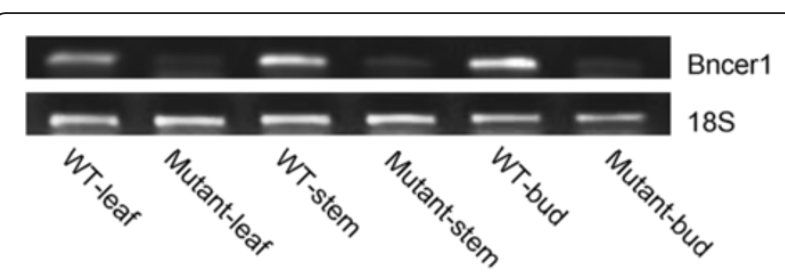

Figure 8 Expression of the BnCER1 gene in WT and the GL mutant. Semi-quantitative RT-PCR. RNA prepared from 4-week-old stems, leaves and buds. 185 rRNA was applied as a constitutively expressed control.
We found that the difference in the genetic linkage maps shown between Figure $6 \mathrm{C}$ to D was the location of BAC "KBrB043F18". Compared to B. rapa, there appears to be an inversion at the end of the B. napus chromosome. We did not get polymorphic markers based on the sequence of the BAC "KBrB043F18", possibly due to the genomic rearrangements on the corresponding region of A9.

All linked markers we detected were on one side of the BnaA.GL gene in B. napus, likely because the gene is located near the end of chromosome. The genome information of $B$. rapa has recently become available, and we made use of information on chromosome synteny between Arabidopsis and B. rapa to conduct genetic and physical comparative mapping of the BnaA.GL locus [37,43-49]. By comparative mapping with B. rapa, the distance from the closest marker and the last annotated gene on R9 is calculated as only $250 \mathrm{~kb}$ [43]. Markers linked to BnaA.GL were used to dissect the microcolinearity of these regions in Arabidopsis and B. rapa. Moreover, SNP markers were developed using an SNP chip assay combined with BSA. This led to the detection of 36 SNPs (Additional file 5), 75\% of which were located in the mapping region. In light of the finding that a homo$\log$ of Arabidopsis CER1, Bra032670, was located in the mapped region of the BnaA.GL, we then amplified and sequenced the Bra032670 from the GL mutant. Bra032670 shares $89 \%$ sequence identity in the coding DNA sequence (CDS) and 99\% at the protein level with the Arabidopsis CER1. However, no apparent sequence alteration was found between WT and the GL mutant, except three SNPs in the fifth intron (Figure 9; Additional file 4).

\section{Wax biosynthetic genes are down-regulated in the glossy mutant}

The reduced expression of multiple wax-related genes uncovered through microarray analysis, beginning from saturated fatty acid biosynthsis to the two branches of the wax biosynthesis pathway, provided a biochemical basis for the phenotype of reduced cuticular wax content. Furthermore, 


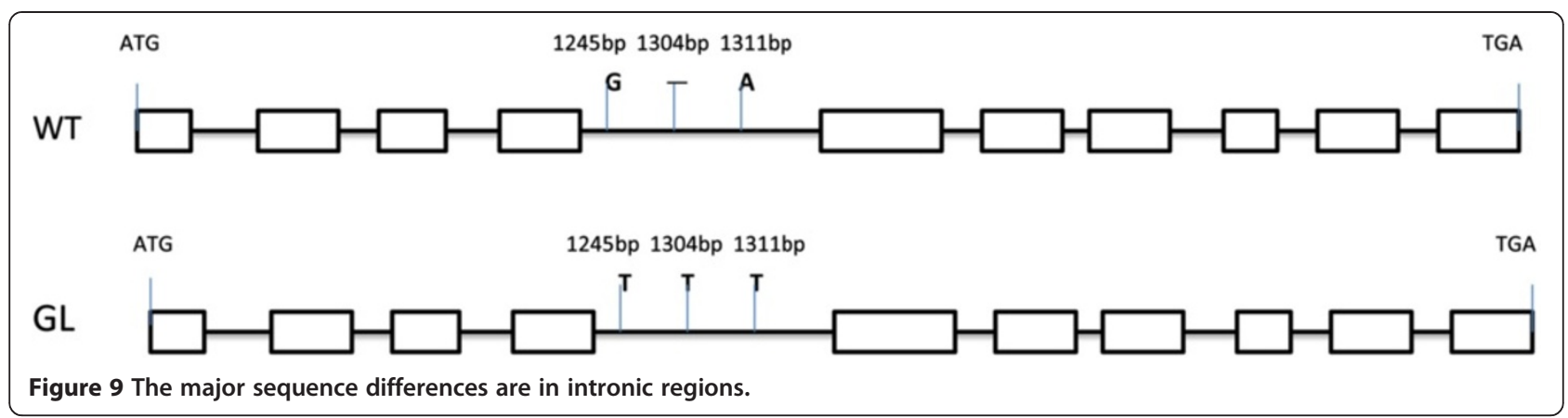

in accordance with the wax compositional changes of the GL mutants, BnCER1 of the decarbonylation pathway of wax biosynthesis was singularly the most severely suppressed gene. Thus, our results show that although the gene Bra032670 encoding BnCER1 was not the genetic lesion in $G L$ mutant, it nonetheless is the primary cause of compromised cuticular wax biosynthesis in the $G L$ mutant. We suggest that the BnaA.GL gene acts as a regulatory factor that targets $B n C E R 1$ and likely the wax biosynthesis pathway as a whole. This supposition is supported by the finding that the midchain alkane hydroxylase (MAH1) and a bifunctional enzyme (WSD1) were also down-regulated $[41,42]$ in the $G L$ mutant. $M A H 1$ is involved in the decarbonylation pathway, catalyzing the hydroxylation of alkanes to secondary alcohols [41]. Some steps of the fatty acid biosynthesis pathway, which is further upstream of the wax decarnylation pathway, were also impacted in the mutant leaf tissues [4]. It must be noted, however, that it is unclear whether the suppression of CER1 resulted in the overall decrease in wax pathway genes or whether CER1 is suppressed as a part of the overall downregulation of the wax pathway, ultimately leading to a deficiency in wax decarbonylation and, consequently, reduced wax deposition.

\section{Conclusions}

The $I W 1, I W 2$ genes in wheat, and the $W x W x$ gene in banana are dominant waxless character genes [23-25]. Except for these genes, however, no dominant glossy mutant has been reported to date. As distinguished from the Arabidopsis cer mutants reported thus far, the BnaA.GL allele behaves in a dominant fashion in regulating wax biosynthesis, although many details remain to be resolved. The glossy phenotype is a classic genetic marker trait in Brassica and could be used as a morphological marker in hybrid breeding. Molecular mapping and cloning of the BnaA.GL genes will also allow novel approaches for manipulating cuticle permeability to increase drought tolerance.

\section{Methods}

\section{Plant materials and growth conditions}

The B. napus glossy mutant 6-1025 (BnaA.GL, from Chengdu Academy of Agriculture and forestry Science) and WT 6-3476 were used in this study. The $F_{2}$ population of 187 plants was derived from the WT $\times G L$ mutant cross. The $F_{1}$ plants were backcrossed with WT for three generations to generate a $\mathrm{BC}_{3} \mathrm{~F}_{1}$ population; the glossy individuals were selfed and the $\mathrm{BC}_{3} \mathrm{~F}_{2}$ seeds were harvested. More than $1200 \mathrm{BC}_{3} \mathrm{~F}_{2}$ individuals were planted, and 300 individuals without a glossy phenotype were used for mapping purposes. The mapping populations were grown in the research field of Huazhong Agricultural University, Wuhan, People's Republic of China.

The plants used for the wax analysis, water permeability analysis and RNA extraction were grown in a soil-based compost under standard greenhouse conditions with a 16-h light/8-h dark cycle. The day/night temperature was $22 / 17^{\circ} \mathrm{C}$ (NRC Saskatoon, SK, Canada).

\section{SEM and TEM analyses}

SEM was used to study the surface of leaves and stems of the mutant and WT plants. Fresh leaves and stems were collected after 4 weeks of growth and fixed overnight in $2 \%$ glutaraldehyde. The ensuing procedures were performed as previously reported [50].

For TEM analysis, fresh leaves and stems were collected from plants after 4 weeks of growth, and the tissue was fixed overnight in $2.5 \%(\mathrm{w} / \mathrm{v})$ glutaraldehyde in $0.1 \mathrm{M}$ phosphate buffer ( $\mathrm{pH} 7.4)$. The ensuing procedures were performed according to a published report [50].

\section{Wax extraction and chemical characterization}

Leaves were collected plants after 4 weeks of growth. Total cuticular wax mixtures were extracted by immersing the leaves in chloroform $\left(\mathrm{CHCl}_{3}\right)$ twice for $30 \mathrm{~s}$ at room temperature. Equal-area round leaf disks were cut using a hole-puncher and used in the wax analysis. For the TLC analysis, the wax mixtures were separated on silica gel 60 using hexane-diethylether-acetic acid 
(90:7.5:1 $[\mathrm{v} / \mathrm{v} / \mathrm{v}])$ and visualized by staining with primuline and UV light $[41,42]$. Each component was extracted from the silica gel, and n-tetracosane (C24 alkane) was added as an internal standard [41]. The solvent was subsequently evaporated under a gentle stream of nitrogen and treated with a mixture of $20 \mu \mathrm{L}$ of bis-N, N-(trimethylsilyl) trifluoroacetamide (Sigma) in pyridine for $1 \mathrm{~h}$ at $70^{\circ} \mathrm{C}$ to convert all the waxes into trimethylsilyl derivatives. The wax composition was determined by capillary GC (6890 N; Agilent) and a mass spectrometric detector (5973 N; Agilent). The initial temperature of $50^{\circ} \mathrm{C}$ was held for $2 \mathrm{~min}$, increased at $40^{\circ} \mathrm{C} / \mathrm{min}$ to $200^{\circ} \mathrm{C}$, held for $2 \mathrm{~min}$ at $200^{\circ} \mathrm{C}$, increased again at $3^{\circ} \mathrm{C} / \mathrm{min}$ to $320^{\circ} \mathrm{C}$ and held for $30 \mathrm{~min}$ at $320^{\circ} \mathrm{C}$. Quantification was based on the flame ionization detector peak areas and the internal standard (C24). The total amount of cuticular wax was expressed per unit of leaf surface area, and the areas were determined by $\pi$. The molecular identities were determined using a GC Agilent 6890 and an Agilent 5973 mass spectrometric detector. The GC program used was according to previous reports [41].

\section{Mapping}

DNA was extracted using a modified CTAB (cetyltrimethylammonium bromide) method [51]. For constructing a rough flanking map linked to the BnaA.GL gene, an $F_{2}$ population consisting of 187 individuals was used. The glossy phenotype as a genetic marker $(\mathrm{Y})$ was used, and a linkage map was constructed as previously reported [52]. A bulk segregant analysis (BSA) combined with the AFLP technique was used to identify molecular markers linked to the Glossy gene (BnaA.GL) [31]. Three plants of each phenotypic class (normal and glossy plants) from the $\mathrm{BC}_{3}$ mapping population were randomly selected for constructing the normal bulk (NB) and glossy bulk (GB). The AFLP analysis and conversion of AFLP markers into SCAR markers were performed as previously described by Zeng et al. [53]. The IP and SSR marker development was performed as previously described by Xia et al. [39]. For primers used in mapping see Additional file 6.

A SNP polymorphism analysis was performed using SNP chip assay combined with BSA. WT, mutant, normal bulk (NB) and glossy bulk (GB) individuals were genotyped using the Illumina Brassica $60 \mathrm{~K}$ Beadchip developed by an international Brassica SNP array Consortium, which was led by AAFC (Agriculture and Agri-Food, Canada). Genotyping was performed according to the manufacturer's recommendations using the Illumina iScan System (Illumina Inc., San Diego, CA).

Subsequently, a $\mathrm{BC}_{3} \mathrm{~F}_{2}$ population consisting of more than 1200 individuals was generated, and 300 individuals with wax from this population were used. The data of these markers and individual phenotypes were analyzed with the MAP-MAKER/EXP 3.0 program [54]. All the markers linked to genes were used to compare the microcolinearity of the regions flanking the genes with $B$. rapa and Arabidopsis, as indicated in previous reports [39].

\section{cDNA microarray assay}

WT, GL mutant and DH line bulks based on phenotype were used. Three independent RNA samples for each were assayed and analyzed. Total RNA of 4-week-old leaves was extracted using the RNeasy Plant Mini Kit (Qiagen).

Approximately $500 \mathrm{ng}$ total RNA was reverse transcribed using Message ${ }^{\mathrm{Tm}}$ II aRNA Amplification Kit (Ambion) according to the manufacturer's protocol. A single dye (Cy5) was used for labeling (Kreatch diagnostics).

A total of 12 independent hybridizations were performed using the Combimatrix Brassica $90 \mathrm{~K}$ microarray produced at the NRC-PBI (National Research Council Plant Biotechnology Institute) (The Hybridization Custom Array $^{\mathrm{Tm}} 90$ K Microarray: Protocol PTL020). Over 94,000 unique DNA probes were synthesized in situ using the patented Combimatrix virtual-flask technology. The semiconductor-based arrays consist of 29 row $\times 34$ column spots. Data collection was performed as previously described by Zhu et al. [55].

$\mathrm{R}$ software was used to statistically analyze the microarray data. Data preprocessing and DEG detection were conducted with the bioconductor [56] packages limma [57] and RankProd [58], respectively. DEGs were selected with FDR $<0.05$ as a threshold. The GO term classification of the DEGs was completed according to ATH_GO_GOSLIM from TAIR [59].

\section{Analysis of transcription levels by quantitative RT-PCR and semiquantitative RT-PCR}

The primer pairs for the quantitative real-time RT-PCR and semiquantitative RT-PCR were specific for the genes and designed to cover an 80-200-bp region (Additional file 6). First-strand cDNAs were synthesized in a $20-\mu \mathrm{L}$ reaction volume containing approximately $1 \mu \mathrm{g}$ RNA using the PrimeScript ${ }^{\mathrm{Tx}}$ 1st Strand cDNA Synthesis Kit (Takara) with oligo dT primers. BnACTIN was applied as an endogenous control for standardization for the real-time PCR templates, and total RNA was extracted from 6-week-old leaves. Quantitative RT-PCR was performed using SYBR Green Real-time PCR Master Mix (TOYOBO) with $0.8 \mu \mathrm{L}$ of each primer $(10 \mu \mathrm{M})$ and $1 \mu \mathrm{L}$ of $1: 100$ diluted cDNA template in a $20-\mu \mathrm{l}$ reaction mixture. The results from three biological replicates are shown.

For semiquantitative real-time PCR templates, $18 \mathrm{~S}$ rRNA was applied as an endogenous control. Amplified PCR products $(10 \mu \mathrm{L})$ were resolved on a $1 \%(\mathrm{w} / \mathrm{v})$ agarose gel with $1 \times$ TBE running buffer. 


\section{Toluidine blue (TB) test}

Toluidine blue is a metachromatic dye that can bind to free anionic groups, such as carboxylate and phosphate. The TB test is able to evaluate water permeability due to surface deficiency, as described previously [33,60,61]. Leaves and stems from four-week-old plants were incubated in an aqueous solution of $0.05 \%(\mathrm{w} / \mathrm{v})$ Toluidine blue for $2 \mathrm{~min}$ and then rinsed with water to remove excess $\mathrm{TB}$ from the leaf surface.

\section{Chlorophyll measurements}

The leaves of 4-week-old plants were used for chlorophyll measurement. Approximately $2 \mathrm{~g}$ of each leaf sample was incubated on ice for $20 \mathrm{~min}$ and immersed in $40 \mathrm{~mL}$ of $80 \%$ ethanol in $50-\mathrm{mL}$ aluminum foilwrapped conical tubes at room temperature. Aliquots of $500 \mu \mathrm{l}$ were removed from the solution every $20 \mathrm{~min}$ after the initial immersion. The amount of extracted chlorophyll was quantified by measuring the absorbance at 647 and $664 \mathrm{~nm}$ using a spectrophotometer, as described previously [62]. We calculated the concentration of total chlorophyll in the fresh leaf tissue using the following equation: total micromoles chlorophyll = 7.93(A664) + 19.53(A647). Chlorophyll efflux during each interval was expressed as a percentage of the chlorophyll over the total chlorophyll extracted after $24 \mathrm{~h}[62]$.

\section{Measurement of water loss}

For the water loss rate analysis, 4-week-old leaves were excised and soaked in water for $60 \mathrm{~min}$ in the dark. The leaves were dried and weighed at the indicated time points at room temperature and dried in a $70^{\circ} \mathrm{C}$ oven overnight until the dry weight was constant. Total water was calculated as the fresh weight minus the dry weight after the heat treatment. The water loss at each interval was expressed as a percentage of the water loss over the total water $[7,10]$.

\section{Availability of supporting data}

Results for the cDNA microarray assays are available through ArrayExpress http://www.ebi.ac.uk/arrayexpress/ website under the accession number E-MEXP-3989.

The sequences of BnCER1 in WT (BnCER1.1) and in GL mutant (BnCER1.2) are available in the NCBI GenBank under the accession numbers KF724897, KF72488, respectively.

\section{Additional files}

Additional file 1: Comparison of water permeability of leaf between WT and GL mutant. Chlorophyll leaching assays (expressed as a percentage of total chlorophyll extracted after $24 \mathrm{~h}$ ). The data represent means of mean values $\pm S E(n=3)$. After 100 min of incubation with alcohol $(80 \% \mathrm{w} / \mathrm{v})$, mutant leaves had lost about $88 \%$ of their chlorophyll, while the WT only lost about $54 \%$. Water loss assays (expressed as a percentage of total water loss after $24 \mathrm{~h}$ ). The data represent means of mean values \pm SE $(n=3)$. The leaf at 4 weeks post emergency excised and soaked in water for $60 \mathrm{~min}$ in the dark. They were dried and weighed per $60 \mathrm{~min}$

Additional file 2: Explanations to microarray data.

Additional file 3: Functional classification of genes. The number follows the term indicate the number of DEGs in this class. Functional classification of up-regulated genes in WT VS mutant. A. Functional classification of up-regulated genes in DHNB VS DHGB. B. Functional classification of up-regulated genes in both comparation. C. Functional classification of down-regulated genes in WT VS mutant. D. Functional classification of down-regulated genes in DHNB VS DHGB. Functional classification of down-regulated genes in both comparation.

Additional file 4: The major sequence differences between the WT and $G L$ mutant.

Additional file 5: Most of the detected SNPs were located on chromosome N9.

Additional file 6: Primers used in this study.

\section{Abbreviations}

CER: ECERIFERUM; VLCFA: Very long-chain fatty acid; DH: Double haploid: SEM: Scanning electron microscopy; TEM: transmission electron microscopy; TB: Toluidine Blue; TLC: Thin-layer chromatography; AFLP: Amplified fragment-length polymorphism; SCAR: Sequence-characterized amplified region; SNP: Single-nucleotide polymorphism; BSA: With bulk segregant analysis; IP: Intron polymorphism; SSR: Two single sequence repeat; BAC: Bacterial artificial chromosome; BCCP: Biotin carboxyl carrier protein; FATB: Fatty acyl-ACP thioesterases B; MAH1: Midchain alkane hydroxylase; WSD1: Bifunctional enzyme wax synthase.

\section{Competing interests}

The authors have declared that no competing interests exist.

\section{Authors' contributions}

YP, JS and JZ designed and supervised the study, JT, TF and CM participated in its design. JG carried out the microarray data analysis. YG and LZ participated in the mapping. YP carried out the microarray chip hybrid analysis, biochemical and RT-PCR analysis. JW, PX and TL participated in the statistical analysis. BY participated in SNP chip assays. YP and JZ wrote the manuscript. All the authors discussed the results and contributed to the manuscript. All authors read and approved the final manuscript.

\section{Acknowledgements}

We thank Dr. Wenyun Shen, Dr. Yongguo Cao, Dr. Daoquan Xiang, Dr. John Li, Dr. Liping Wang (National Research Council Canada, SK) and Dr. Mei Bai (South China Agricultural University) for technical support, and thank Dr. Daiqing Huang (National Research Council Canada, SK) and Dr. Shengqian Xia for helpful discussions and suggestions. We greatly acknowledge the efforts of Dr. Mayank Gautam and Dr. Patricia Vrinten for thoroughly reading and editing the English of the manuscript.

The author YP would like to acknowledge the financial support from China Scholarship Council for one year's study at the National Research Council Canada, Saskatoon. This research was financially supported by National High-Tech R\&D Program (863 Program) (grant number 2011AA10A104) and Program for Modern Agricultural Industrial Technology System (nycytx-00501).

\section{Author details}

${ }^{1}$ National Key Laboratory of Crop Genetic Improvement, Huazhong Agricultural University, Wuhan 430070, China. ${ }^{2}$ National Research Council Canada, Saskatoon, Saskatchewan S7N 0 W9, Canada.

Received: 27 June 2013 Accepted: 5 December 2013

Published: 14 December 2013 


\section{References}

1. Jetter R, Kunst L, Samuels AL: Composition of plant cuticular waxes. In Biology of the plant cuticle. Edited by Riederer M, Müller C. Oxford: Blackwell; 2006:145-181.

2. Bernard A, Joubes J: Arabidopsis cuticular waxes: advances in synthesis, export and regulation. Prog Lipid Res 2013, 52(1):110-129.

3. Eigenbrode SD, Espelie KE: Effects of plant epicuticular lipids on insect herbivores. Annu Rev Entomol 1995, 40:171-194.

4. Li-Beisson Y, Shorrosh B, Beisson F, Andersson MX, Arondel V, Bates PD, Baud S, Bird D, Debono A, Durrett TP, et al: Acyl-lipid metabolism. In The Arabidopsis book. Rockville MD: American Society of Plant Biologists; 2010:8-e0133.

5. Kosma DK, Bourdenx B, Bernard A, Parsons EP, Lu S, Joubes J, Jenks MA: The impact of water deficiency on leaf cuticle lipids of Arabidopsis. Plant Physiol 2009, 151(4):1918-1929.

6. Shepherd T, Wynne Griffiths D: The effects of stress on plant cuticular waxes. New Phytol 2006, 171(3):469-499.

7. Seo PJ, Lee SB, Suh MC, Park MJ, Go YS, Park CM: The MYB96 transcription factor regulates cuticular wax biosynthesis under drought conditions in Arabidopsis. Plant Cell 2011, 23(3):1138-1152.

8. Chen X: Cloning and characterization of the WAX2 gene of Arabidopsis involved in cuticle membrane and wax production. Plant Cell Online 2003, 15(5):1170-1185.

9. Lü S, Song T, Kosma DK, Parsons EP, Rowland O, Jenks MA: Arabidopsis CER8 encodes LONG-CHAIN ACYL-COA SYNTHETASE 1 (LACS1) that has overlapping functions with LACS2 in plant wax and cutin synthesis. Plant J 2009, 59(4):553-564.

10. Weng H, Molina I, Shockey J, Browse J: Organ fusion and defective cuticle function in a lacs1 lacs2 double mutant of Arabidopsis. Planta 2010, 231(5):1089-1100.

11. Islam MA, Du H, Ning J, Ye H, Xiong L: Characterization of Glossy1-homologous genes in rice involved in leaf wax accumulation and drought resistance. Plant Mol Biol 2009, 70(4):443-456.

12. Yu D, Ranathunge K, Huang H, Pei Z, Franke R, Schreiber L, He C: Wax Crystal-Sparse Leaf1 encodes a beta-ketoacyl CoA synthase involved in biosynthesis of cuticular waxes on rice leaf. Planta 2008, 228(4):675-685.

13. Saladié M, Matas AJ, Isaacson T, Jenks MA, Goodwin SM, Niklas KJ, Xiaolin R, Labavitch JM, Shackel KA, Fernie AR, et al: A reevaluation of the key factors that influence tomato fruit softening and integrity. Plant Physiol 2007, 144(2):1012-1028

14. Leide J, Hildebrandt U, Reussing K, Riederer M, Vogg G: The developmental pattern of tomato fruit wax accumulation and its impact on cuticular transpiration barrier properties: effects of a deficiency in a beta-ketoacylcoenzyme A synthase (LeCER6). Plant Physiol 2007, 144(3):1667-1679.

15. Kurata T, Kawabata-Awai C, Sakuradani E, Shimizu S, Okada K, Wada T: The YORE-YORE gene regulates multiple aspects of epidermal cell differentiation in Arabidopsis. Plant J 2003, 36(1):55-56.

16. Fiebig A, Mayfield JA, Miley NL, Chau S, Fischer RL, Preuss D: Alterations in CER6, a gene identical to CUT1, differentially affect long-chain lipid content on the surface of pollen and stems. Plant Cell 2000, 12(10):2001-2008.

17. Rashotte AM, Jenks MA, Nguyen TD, Feldmann KA: Epicuticular wax variation in ecotypes of Arabidopsis thaliana. Phytochemistry 1997, 45(2):251-255.

18. Samuels $L$, Kunst $L$, Jetter R: Sealing plant surfaces: cuticular wax formation by epidermal cells. Annu Rev Plant Biol 2008, 59:683-707.

19. Aarts MG, Keijzer CJ, Stiekema WJ, Pereira A: Molecular characterization of the CER1 gene of Arabidopsis involved in epicuticular wax biosynthesis and pollen fertility. Plant Cell 1995, 7(12):2115-2127.

20. Bourdenx B, Bernard A, Domergue F, Pascal S, Leger A, Roby D, Pervent M, Vile D, Haslam RP, Napier JA, et al: Overexpression of Arabidopsis ECERIFERUM1 promotes wax very-long-chain alkane biosynthesis and influences plant response to biotic and abiotic stresses. Plant Physiol 2011, 156(1):29-45.

21. McNevin JP, Woodward W, Hannoufa A, Feldmann KA, Lemieux B: Isolation and characterization of eceriferum (cer) mutants induced by T-DNA insertions in Arabidopsis thaliana. Genome 1993, 36(3):610-618.

22. Bernard A, Domergue F, Pascal S, Jetter R, Renne C, Faure JD, Haslam RP, Napier JA, Lessire R, Joubes J: Reconstitution of plant alkane biosynthesis in yeast demonstrates that Arabidopsis ECERIFERUM1 and ECERIFERUM3 are core components of a very-long-chain alkane synthesis complex. Plant Cell 2012, 24(7):3106-3118.
23. Zhang Z, Wang W, Li W: Genetic interactions underlying the biosynthesis and inhibition of beta-diketones in wheat and their impact on glaucousness and cuticle permeability. PloS One 2013, 8(1):e54129.

24. Adamski NM, Bush MS, Simmonds J, Turner AS, Mugford SG, Jones A, Findlay K, Pedentchouk N, Von Wettstein-Knowles P, Uauy C: The Inhibitor of wax 1 locus (IW1) prevents formation of beta- and OH-beta-diketones in wheat cuticular waxes and maps to a sub-cM interval on chromosome arm 2BS. Plant J 2013, 74(6):989-1002.

25. Ortiz R, Vuylsteke D, Ogburia NM: Inheritance of Pseudostem Waxiness in Banana and Plantain (Musa spp.). J Heridity 1995, 86(4):297-299.

26. Kunst L, Samuels AL: Biosynthesis and secretion of plant cuticular wax. Prog Lipid Res 2003, 42(1):51-80.

27. Hannoufa A, McNevin J, Lemieux B: Epicuticular waxes of eceriferum mutants of Arabidopsis thaliana. Phytochemistry 1993, 33(4):851-855.

28. Mo JG, Li WG, Wang JS: Inheritance and agronomic performance of the waxless character in Brassica napus L. Plant Breed 1992, 108:256-259.

29. Zhou XR, Zhou ZJ, Li SL: Inheritance of waxless character in Rapseed (B.napus L.). Acta Agriculturae Shanghai 1995, 11(3):87-89.

30. Zhang X, Liu ZY, Wang P, Wang QS, Yang S, Feng H: Fine mapping of $B r W a x 1$, a gene controlling cuticular wax biosynthesis in Chinese cabbage (Brassica rapa L. ssp. pekinensis). Mol Breed 2013, 32(4):867-874. doi:10.1007/s1 1032-013-9914-0.

31. Zeng X, Wen J, Wan Z, Yi B, Shen J, Ma C, Tu J, Fu T: Effects of Bleomycin on microspore embryogenesis in Brassica napus and detection of somaclonal variation using AFLP molecular markers. Plant Cell Tiss Org Cult 2009, 101(1):23-29.

32. Li C, Wang A, Ma X, Pourkheirandish M, Sakuma S, Wang N, Ning S, Nevo E, Nawrath C, Komatsuda T, et al: An eceriferum locus, cer-zv, is associated with a defect in cutin responsible for water retention in barley (Hordeum vulgare) leaves. Theor Appl Genet 2013, 126(3):637-646.

33. Tanaka T, Tanaka H, Machida C, Watanabe M, Machida Y: A new method for rapid visualization of defects in leaf cuticle reveals five intrinsic patterns of surface defects in Arabidopsis. Plant J 2004, 37(1):139-146.

34. Lu S, Zhao H, Parsons EP, Xu C, Kosma DK, Xu X, Chao D, Lohrey G, Bangarusamy DK, Wang G, et al: The glossyhead1 allele of $A C C 1$ reveals a principal role for multidomain acetyl-coenzyme A carboxylase in the biosynthesis of cuticular waxes by Arabidopsis. Plant Physiol 2011, 157(3):1079-1092.

35. Michelmore RW, Paran I, Kesseli RV: Identification of markers linked to disease-resistance genes by bulked segregant analysis: a rapid method to detect markers in specific genomic regions by using segregating populations. Proc Natl Acad Sci U S A 1991, 88(21):9828-9832.

36. Kim H, Choi SR, Bae J, Hong CP, Lee SY, Hossain MJ, Van Nguyen D, Jin M, Park BS, Bang JW, et al: Sequenced BAC anchored reference genetic map that reconciles the ten individual chromosomes of Brassica rapa. BMC Genomics 2009, 10:432

37. Wang X, Wang H, Wang J, Sun R, Wu J, Liu S, Bai Y, Mun JH, Bancroft I, Cheng F, et al: The genome of the mesopolyploid crop species Brassica rapa. Nat Genet 2011, 43(10):1035-1039.

38. Wang J, Long Y, Wu B, Liu J, Jiang C, Shi L, Zhao J, King GJ, Meng J: The evolution of Brassica napus FLOWERING LOCUS T paralogues in the context of inverted chromosomal duplication blocks. BMC Evol Biol 2009, 9:271

39. Xia S, Cheng L, Zu F, Dun X, Zhou Z, Yi B, Wen J, Ma C, Shen J, Tu J, et al: Mapping of BnMs4 and BnRf to a common microsyntenic region of Arabidopsis thaliana chromosome 3 using intron polymorphism markers. Theor Appl Genet 2012, 124(7):1193-1200.

40. Wen M, Jetter R: Composition of secondary alcohols, ketones, alkanediols, and ketols in Arabidopsis thaliana cuticular waxes. J Exp Bot 2009, 60(6):1811-1821.

41. Greer S, Wen M, Bird D, Wu X, Samuels L, Kunst L, Jetter R: The cytochrome P450 enzyme CYP96A15 is the midchain alkane hydroxylase responsible for formation of secondary alcohols and ketones in stem cuticular wax of Arabidopsis. Plant Physiol 2007, 145(3):653-667.

42. Li F, Wu X, Lam P, Bird D, Zheng H, Samuels L, Jetter R, Kunst L: Identification of the wax ester synthase/acyl-coenzyme A: diacylglycerol acyltransferase WSD1 required for stem wax ester biosynthesis in Arabidopsis. Plant Physiol 2008, 148(1):97-107.

43. Cheng F, Liu S, Wu J, Fang L, Sun S, Liu B, Li P, Hua W, Wang X: BRAD, the genetics and genomics database for Brassica plants. BMC Plant Biol 2011, 11:136. 
44. Cheng F, WU J, Fang L, Wang X: Syntenic gene analysis between Brassica rapa and other Brassicaceae species. Front Plant Sci 2012, 3:198.

45. Parkin IA, Gulden SM, Sharpe AG, Lukens L, Trick M, Osborn TC, Lydiate DJ: Segmental structure of the Brassica napus genome based on comparative analysis with Arabidopsis thaliana. Genetics 2005, 171(2):765-781.

46. Zhao J, Huang J, Chen F, Xu F, Ni X, Xu H, Wang Y, Jiang C, Wang H, Xu $A$, et al: Molecular mapping of Arabidopsis thaliana lipid-related orthologous genes in Brassica napus. Theor Appl Genet 2012 124(2):407-421.

47. Rana D, van den Boogaart T, O'Neill CM, Hynes L, Bent E, Macpherson L, Park JY, Lim YP, Bancroft I: Conservation of the microstructure of genome segments in Brassica napus and its diploid relatives. Plant J 2004, 40(5):725-733.

48. Lagercrantz U, Lydiate DJ: Comparative genome mapping in Brassica. Genetics 1996, 144(4):1903-1910.

49. Lukens L, Zou F, Lydiate D, Parkin I, Osborn T: Comparison of a Brassica oleracea genetic map with the genome of Arabidopsis thaliana. Genetics 2003, 164(1):359-372.

50. Yi B, Zeng F, Lei S, Chen Y, Yao X, Zhu Y, Wen J, Shen J, Ma C, Tu J, et al: Two duplicate CYP704B1-homologous genes BnMs1 and BnMs2 are required for pollen exine formation and tapetal development in Brassica napus. Plant J 2010, 63(6):925-938.

51. Doyle JJ, Doyle JL: Isolation of plant DNA from fresh tissue. Focus 1990 12:13-15.

52. Chen W, Zhang Y, Liu X, Chen B, Tu J, Tingdong F: Detection of QTL for six yield-related traits in oilseed rape (Brassica napus) using $\mathrm{DH}$ and immortalized F(2) populations. Theor App/ Genet 2007, 115(6):849-858.

53. Zeng X, Zhu L, Chen Y, Qi L, Pu Y, Wen J, Yi B, Shen J, Ma C, Tu J, et al: Identification, fine mapping and characterisation of a dwarf mutant (bnaC.dwf) in Brassica napus. Theor Appl Genet 2011, 122(2):421-428.

54. Lincoln S, Daly M, Lander E: Constructing genetic linkage maps with Mapmaker/exp 3.0: a tutorial and reference manual, 3rd edn. Cambridge, MA: Whitehead Institute,1992,Technical Report; 1992.

55. Zhu Y, Cao Z, Xu F, Huang Y, Chen M, Guo W, Zhou W, Zhu J, Meng J, Zou $\mathrm{J}$, et al: Analysis of gene expression profiles of two near-isogenic lines differing at a QTL region affecting oil content at high temperatures during seed maturation in oilseed rape (Brassica napus L.). Theor Appl Genet 2012, 124(3):515-531.

56. Bioconductor. http://www.bioconductor.org

57. Smyth GK: Limma: linear models for microarray data. In Bioinformatics and Computational Biology Solutions using $R$ and Bioconductor. Edited by Gentleman R, Carey V, Huber W, Irizarry R. New York: Springer New York; 2005:397-420.

58. Hong F, Breitling R, McEntee CW, Wittner BS, Nemhauser JL, Chory J: RankProd: a bioconductor package for detecting differentially expressed genes in meta-analysis. Bioinformatics 2006, 22(22):2825-2827.

59. Tair. http://www.arabidopsis.org.

60. Kurdyukov S, Faust A, Nawrath C, Bar S, Voisin D, Efremova N, Franke R, Schreiber L, Saedler H, Metraux JP, et al: The epidermis-specific extracellular BODYGUARD controls cuticle development and morphogenesis in Arabidopsis. Plant Cell 2006, 18(2):321-339.

61. Xiao F, Goodwin SM, Xiao Y, Sun Z, Baker D, Tang X, Jenks MA, Zhou JM: Arabidopsis CYP86A2 represses Pseudomonas syringae type III genes and is required for cuticle development. EMBO J 2004, 23(14):2903-2913.

62. Kimbara J, Yoshida M, Ito H, Hosoi K, Kusano M, Kobayashi M, Ariizumi T, Asamizu E, Ezura H: A novel class of sticky peel and light green mutations causes cuticle deficiency in leaves and fruits of tomato (Solanum lycopersicum). Planta 2012, 236(5):1559-1570.

doi:10.1186/1471-2229-13-215

Cite this article as: Pu et al:: A novel dominant glossy mutation causes suppression of wax biosynthesis pathway and deficiency of cuticular wax in Brassica napus. BMC Plant Biology 2013 13:215.

\section{Submit your next manuscript to BioMed Central and take full advantage of:}

- Convenient online submission

- Thorough peer review

- No space constraints or color figure charges

- Immediate publication on acceptance

- Inclusion in PubMed, CAS, Scopus and Google Scholar

- Research which is freely available for redistribution

Submit your manuscript at www.biomedcentral.com/submit
Biomed Central 